\title{
Structural and Thermal Analysis of Disc Brake with Slots
}

\author{
K. Viswanath Allamraju, B. Sathya Sai Swaroop, K. Sharath Kumar, Ch. Vaishnavi Srinivas
}

\begin{abstract}
The design of braking system of a vehicles is very important in order to minimize the accidents and increase the life span of vehicle, with this motto, in this paper presented the structural analysis, fatigue analysis and thermal analysis of disc brake with slots (DBS) is done by considering various materials of DBS such as carbon alloy, steel and carbon steel. The comparison of those materials is studied in various mechanical and thermal properties such as deformation, strain, stress, factor of safety, number cycles under cyclic loading and heat flux. Simulation studies were done in Ansys 14.5 version. It is observed that the heat flow rate is high in carbon alloy and low in carbon steel material of DBS model. Maximum stress is observed in steel in structural analysis.
\end{abstract}

Index Terms: Cabon alloy, Carbon steel, DBS model, Steel, Thermal analysis.

\section{INTRODUCTION}

Braking system is one amongst the vital safety parts of a vehicle. It's primarily wont to decelerate vehicles from an initial speed to a given speed. A friction based mostly braking system is a typical device to convert mechanical energy into thermal energy through a friction between the restraint and also the rotor faces. as a result of high temperatures will result in heating of the brake fluid, seals and different parts, the stopping capability of a brake will increase with the speed at that heat is dissipated because of forced convection and thermal capability of the system [1].Brake disc convective cooling has been traditionally studied by suggests that of experimental and theoretical strategies [2, 3] and also the improvement was solely boosted with the arrival of contemporary procedure resources within the late Eighties [4]. Currently, though of not easy usage and requiring previous understanding of the fundamentals of hydraulics and warmth transfer plus the information of numerical flow modeling,

procedure fluid dynamics (CFD) has signifi- cantly gained preference within the automotive trade style method as a tool for the prediction of advanced flow and warmth transfer

Revised Manuscript Received on February 05, 2020.

* Correspondence Author

K.Viswanath Allamraju*, Mechanical Engineering, Institute of Aeronautical Engineering, Hyderabad, India. akvn87@gmail.com.

B. Sathya Sai Swaroop, Mechanical Engineering, Institute of Aeronautical Engineering, Hyderabad, India.

K. Sharath Kumar, Mechanical Engineering, Institute of Aeronautical Engineering, Hyderabad, India.

Ch. Vaishnavi Srinivas, Mechanical Engineering, Institute of Aeronautical Engineering, Hyderabad, India.

(C) The Authors. Published by Blue Eyes Intelligence Engineering and Sciences Publication (BEIESP). This is an open access article under the CC BY-NC-ND license (http://creativecommons.org/licenses/by-nc-nd/4.0/) behavior in regions, wherever otherwise terribly heavy and time overwhelming experimental originated work would be required. As a result, brake disc convective cool- ing analysis and improvement is these days principally allotted victimization CFD business codes, see, e.g., [5]. Many investigations of warmth flow through aired disc brakes square measure reportable within the literature. Morgon et al. [6] distributed a numerical study exploitation the software package Fluent on disc rotor blades to look at the results of native heat and mass transfer of the axial gap distances for one co-rotating disc. The study of the one rotating disc showed that heat and mass transfer coefficients square measure increased significantly by decreasing the hub height. The friction heat generated between two slippery bodies causes thermoelastic deformation that alters the contact pressure distribution. This coupled thermo-mechanical method is referred to because the frictionally-excited thermoelastic instability [5]. Different works have studied the transient brake analysis [7-11]. Zhu et al. established the theoretical model of a three-dimensional (3D) transient temperature field to predict the modification of brake shoe's temperature field throughout hoist's emergency braking [12]. Vold rich postulated that the extraordinary of the essential slippery speed in brake discs causes formation of hot spots, non-uniform contact pressure distribution, vibration, and permanent harm of the disc [13]. Zagrodzki analyzed slippery systems with resistance heating, that exhibit thermoelastic instability (TEI) in friction clutches and brakes once the slippery speed exceeds a essential price [4]. Archangel and Roland mentioned the flowing patterns within the disc rotors [2]. The analytical model of TEI development was revealed by Lee and Barber [3]. Structural and thermal analysis of disc brake with drilled was done in Ansys [16]. In this paper, the fatigue and thermal analysis of DBS model is presented with various materials such as carbon, steel and carbon steel.

\section{STRUCTURAL ANALYSIS OF DBS MODEL}

Geometric properties of DBS model are shown below.

Rotor disc dimension $=240 \mathrm{~mm}$

Pad brake area $=2000 \mathrm{~mm}^{2}$

Pad brake material $=$ asbestos

Coefficient of friction (wet) $=0.07$

Coefficient of friction (dry) $=0.3$

Maximum temperature $=350{ }^{0} \mathrm{C}$

Maximum pressure $=1 \mathrm{MPa}$

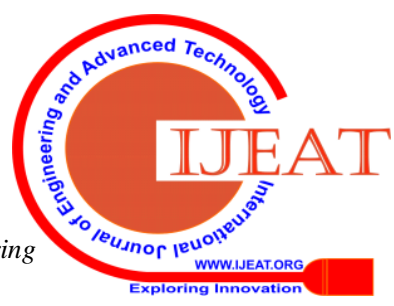


Structural and Thermal Analysis of Disc Brake with Slots

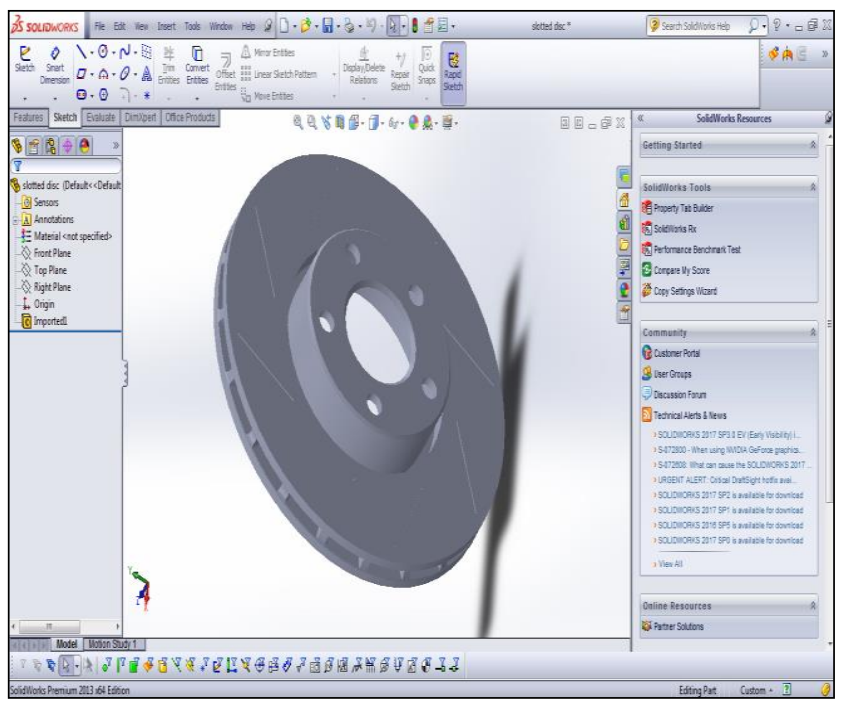

Fig.1Disc brake with slots model(DBS)

Structural analysis, fatigue and thermal analysis are done in Ansys 14.5 Simulation tool but the modeling of plane disc rotor brake was modeled in Solid Works. Fig. 1 presents the 3D model of DBS model. Fig 2, 3 and 4 shows deformation, stress and strain of DBS model made of carbon alloy. Data from structural analysis is required for doing Fatigue analysis, therefore, in this paper; structure analysis is done as a prerequisite for fatigue analysis.

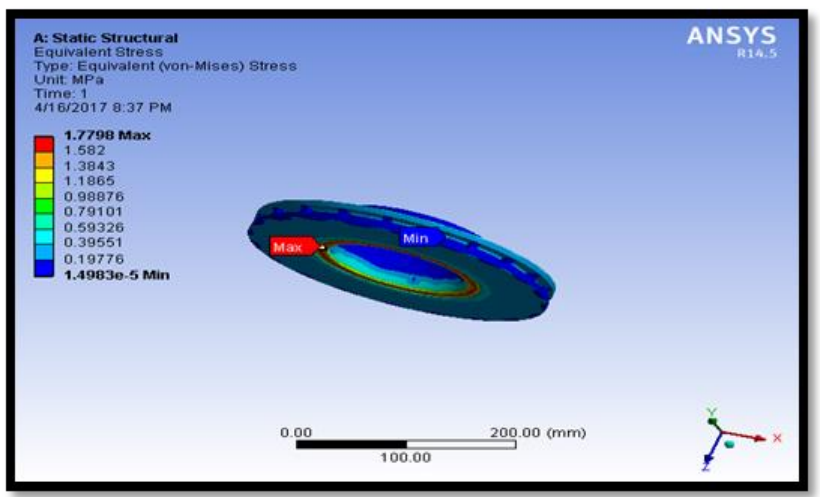

Fig.2. Stress diagram of DBS model of alloy

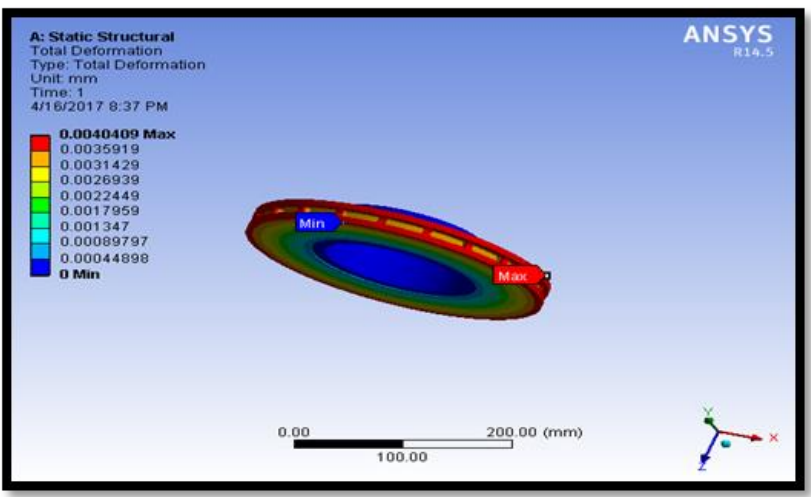

Fig.3. Deformation of DBS model of carbon Alloy

Maximum stress was observed at inner side and minimum stress was observed at outer side of disc.

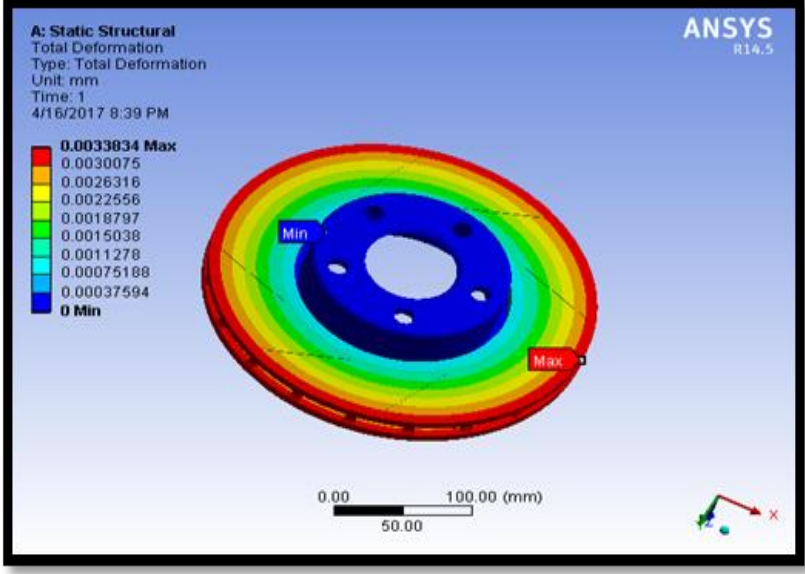

Fig.4. Strain diagram of DBS model of carbon alloy material

Fig. 5 to 7 describe the deformation, stress and strains of DBS made of steel material. Fig. 8 to 10 describes the deformation, stress and strains of DBS made of carbon steel material.

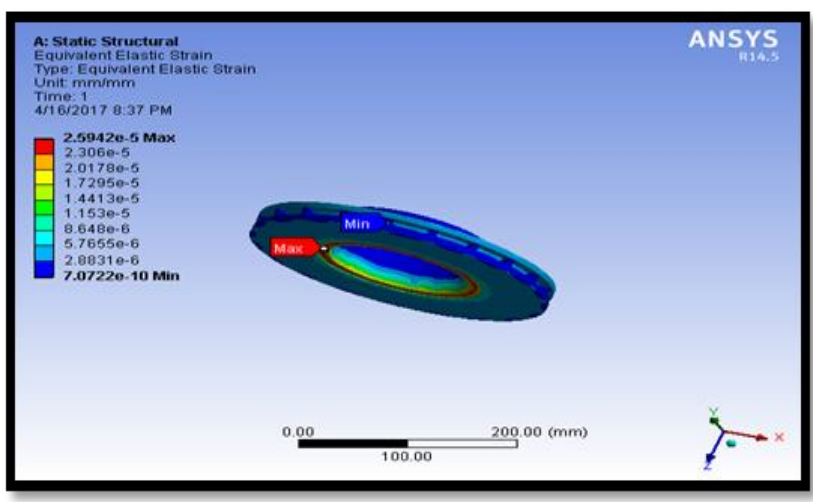

Fig.5. Deformation diagram of DBS model of steel material

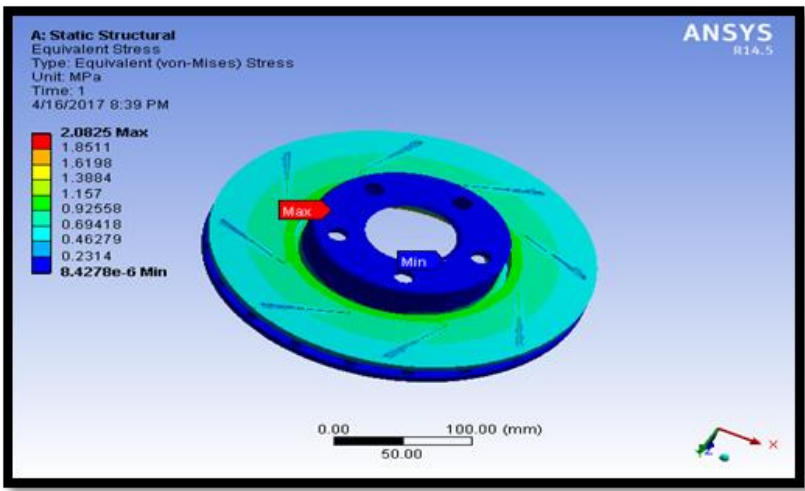

Fig.6. Stress diagram of DBS model of steel material

In this portion, structural analysis figures of carbon alloy DBH, steel DBH and carbon steel DBH are presented. The fatigue and thermal analysis results are mentioned through tables 1,2 and 3.

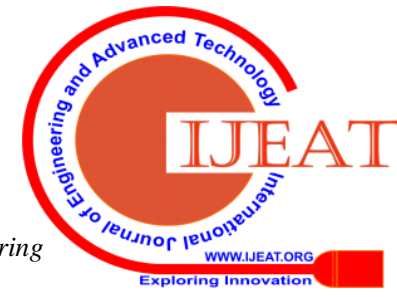




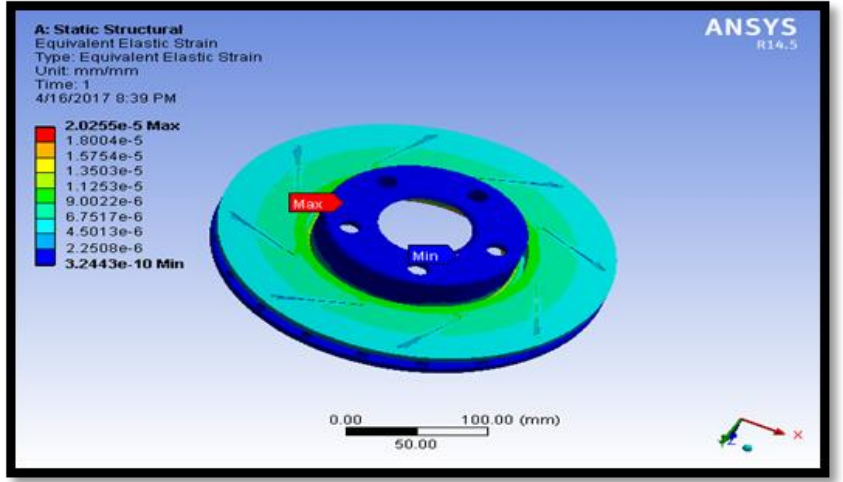

Fig.7. Strain diagram of DBS model of steel material

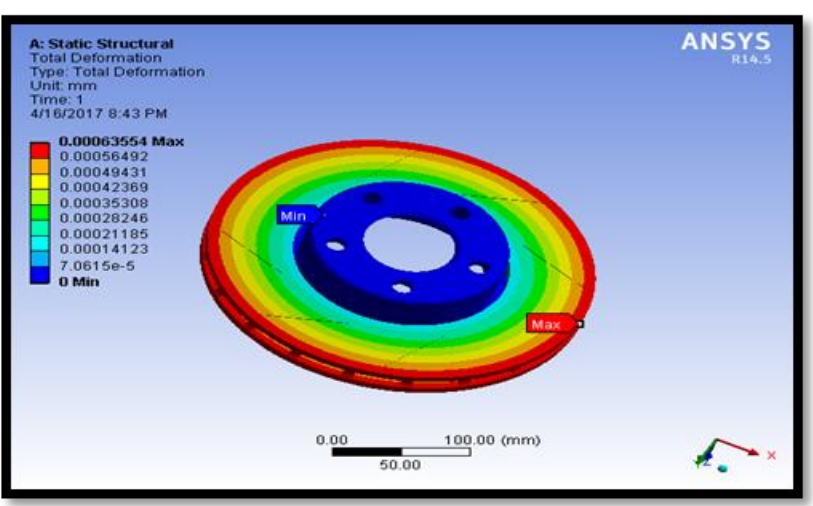

Fig.8. Deformation diagram of DBS model with carbon steel material

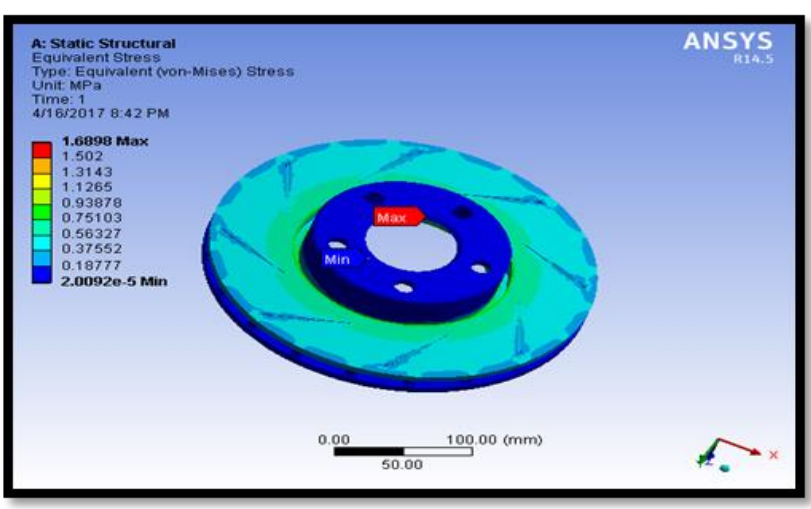

Fig.9. Stress diagram of DBS model with carbon steel material

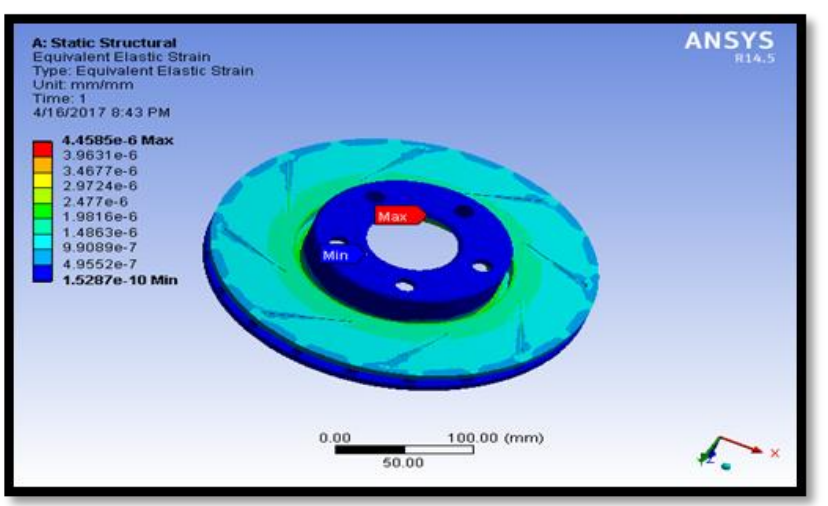

Fig.10. Strain diagram of DBS model with carbon steel material

\section{RESULTS AND DISCUSSION}

Table 1, 2 and 3 gives the simulation values of plane disc with carbon alloy, steel and carbon steel materials during structural analysis, fatigue analysis and thermal analysis Steel refers to the material of stainless steel. Fig.11 and 12 describes the values of deformation and maximum stress in structural analysis and its relation. It is observed that the maximum deformation in carbon alloy and minimum value in carbon steel under constant load. The maximum stress is observed in steel and minimum value in carbon steel. These values are depended on modulus of elasticity of materials. The working stress and the life of DBS can be predicted by using fatigue analysis.

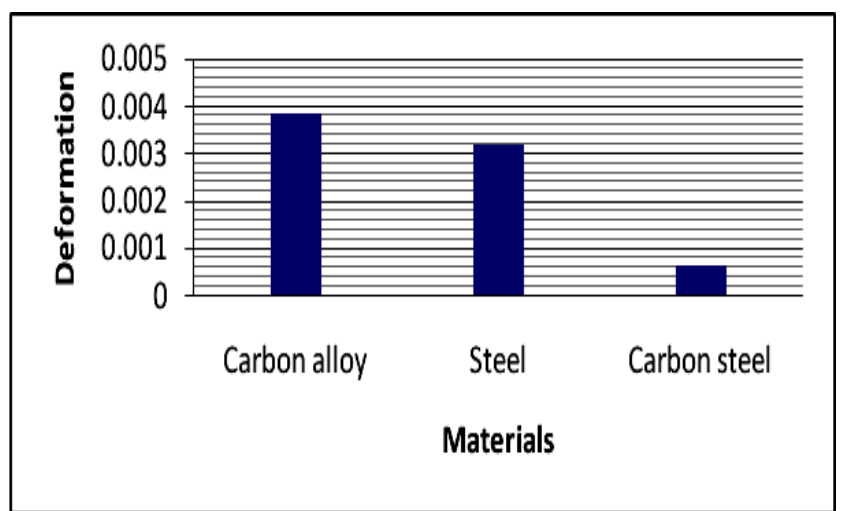

Fig.11. Deformation of CA,S and CS

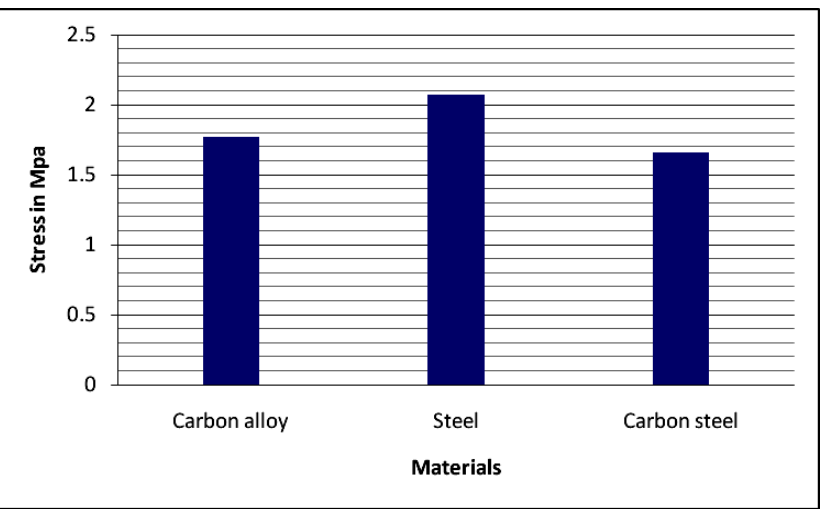

Fig.12. Stress values of DBS model with CA, S and CS

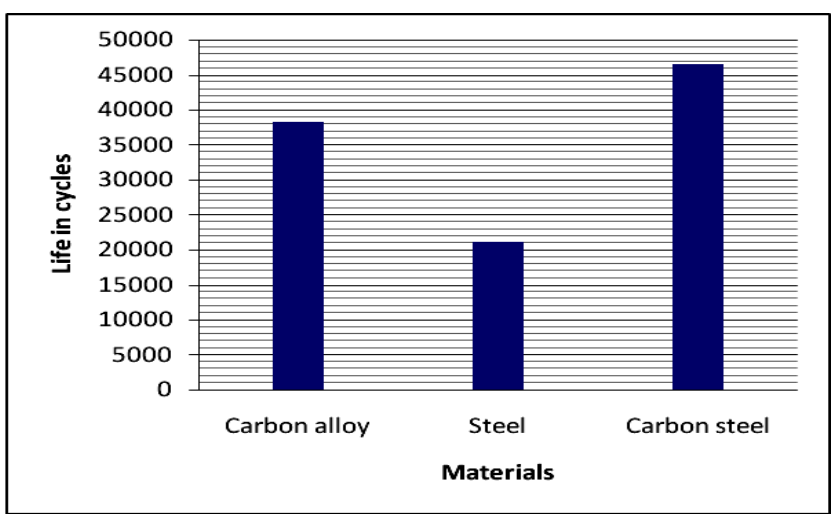

Fig.13. Number of cycles of CA,S and CS

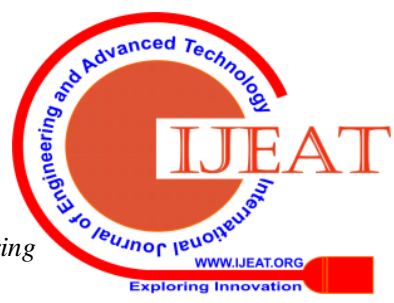




\section{Structural and Thermal Analysis of Disc Brake with Slots}

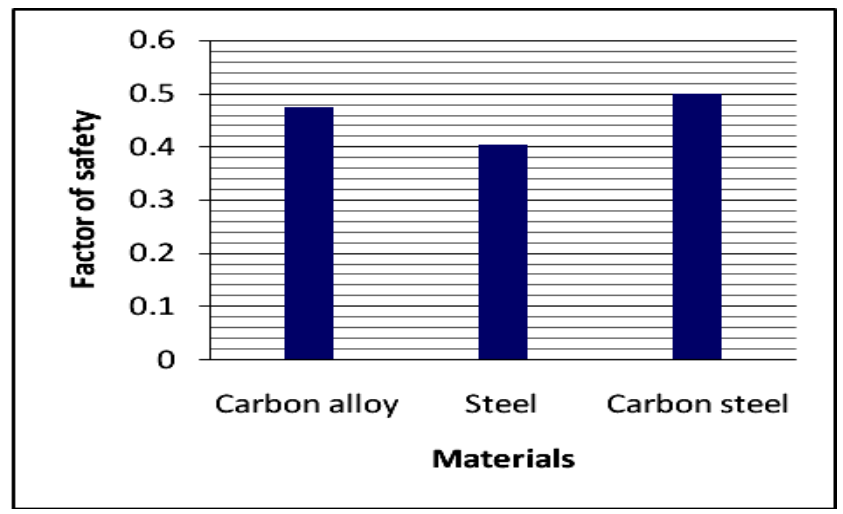

Fig.14. Factor of safety of DBS model of CA,S and CS Factor of safety is observed in carbon alloy, steel and carbon steel by doing fatigue analysis. The maximum values are observed in carbon steel and minimum value in steel (Fig.14). The number of cycles of operation under cyclic load, maximum for carbon steel material and minimum for steel material (Fig.13). If the factor of safety is high, the working cycles under fatigue load is in proportional.

Thermal analysis is done in order determine the heat flux values of DBS made of various materials such as carbon alloy, steel and carbon steel. When the brake is applied to control the speed, the heat will be generated due to contact.

Fig.15 describes the heat flux values of carbon alloy, steel and carbon steel. The maximum heat flux value is observed for carbon alloy and minimum for carbon steel material of DBS.

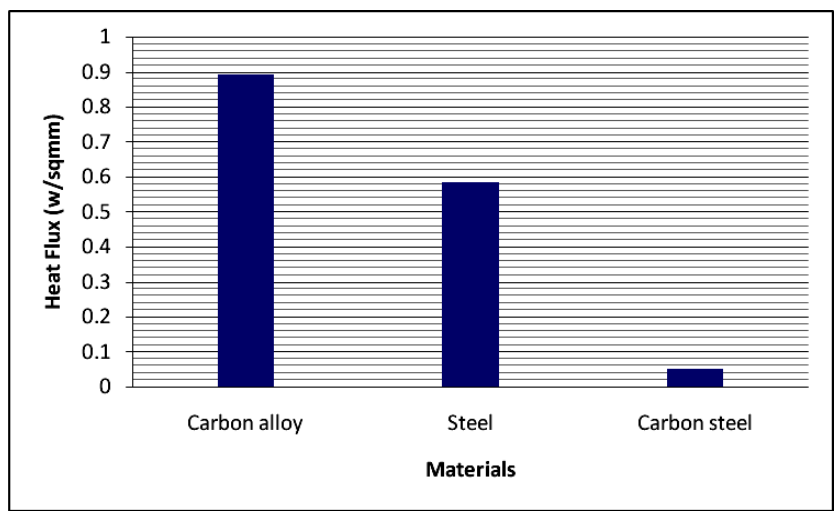

Fig.15. Heat flux of CAS and CS

\section{CONCLUSION}

Structural analysis, fatigue analysis and thermal analysis of DBS model, which was made of carbon alloy, steel and carbon steel is done in order to design the robust disc brake for minimizing the cost and damage. And also fatigue analysis predicts the life of brake under cyclic loads. Carbon steel material could withstand more cycles in comparison to other materials such as carbon alloy and steel under constant load. Heat flow rate is high in carbon alloy material in comparison to steel and carbon steel materials, which was observed from thermal analysis. The conclusion is that simulation of DBS with carbon alloy, steel and carbon steel helps to get optimized design under both cyclical and normal loads.

\section{REFERENCES}

1. Rajagopal, T. K. R., Ramachandran, R., James, M., Gatlewar, S. Ch., Numerical investigation of fluid flow and heat transfer characteristics on the aerodynamics of ventilated disc brake rotor using CFD, Thermal Science 18 (2) 2014, pp. 667-675.

2. Hudson, M., Ruhl, R., Ventilated brake rotor air flow investigation, SAE Technical Paper 971033, 1997.

3. Zhang, J., Xia, C., Research of the transient temperature field and friction properties on disc brakes, Proceedings of the 2nd International Conference on Computer and Information Applica- tion, 2012, pp. 201-204.

4. Zagrodzki, P., Thermoelastic instability in friction clutches and brakes-transient modal analysis revealing mechanisms of excitation of unstable modes, International Journal of Solids and Structures 46 ,2009, pp. 2463-2476.

5. Palmer, E., Fieldhouse, J., Mishra, R., Optimisation of pin shape and its configuration for a pin type vente brake disc using CFD, FISITA, Yokohama, 2006.

6. Morgan, S., Dennis, R., A theoretical prediction of disc brake temperatures and a comparison with experimental data, SAE Technical Paper 720090, 1972

7. Jung, S. P., Park, T. W., Kim, Y. G., A study on thermal characteristic analysis and shape opti- mization of a ventilated disc, Internationa Journal of Precision Engineering and Manufacturing 13 (1)2012,pp. 57-63.

8. Khalid, M. K., Mansor, M. R., Abdul Kudus, S. I., Tahir, M. M., Hassan, M. Z., Performance in- vestigation of the UTeM Eco-Car disc brake system, International Journal of Engineering \& Tech- nology 11 (6) 2011,pp. 1-6.

9. Nouby, M., Abdo, J., Mathivanan, D., Srinivasan, K., Evaluation of disc brake materials for squeal reduction, Tribology Transactions 54 (4) 2011,pp. 644-656.

10. Omolayo, P. M., Ogheneortega, O. J., Numerical simulation of thermoelastic contact problem of disc brake with frictional heat generation, New York Science Journal 5 (10) 2012,pp.39-43.

11. O“ ztu“rk, B., Arslan, F., O“ ztu“rk, S., Effects of different kinds of fibers on mechanical and tribologi- cal properties of brake friction materials, Tribology Transactions 56 (4) 2013, pp. 536-545.

12. Limpert, R., The thermal performance of automotive disc brakes, SAE Technical Paper 750873, 1975.

13. Zhu, Z. C., Peng, U. X., Shi, Z. Y., Chen, G. A., Three-dimensional transient temperature field of brake shoe during hoist's emergency braking, Applied Thermal Engineering 29 (2009) 932-937.

14. Vold rich, J., Frictionally excited thermoelastic instability in disc brakes-transient problem in the full contact regime, International Journal of Mechanical Sciences 49 (2007) 129-137.

15. Dhaubhadel, M. N., Review: CFD applications in the automotive industry, Journal of Fluids En- gineering 118 (4) 1996, pp.647-653.

16. K Viswanath Allamraju, Ravi Kumar Arrola, Structural and Thermal analysis of disc brake with drilled holes of various materials, IJITEE, Vol 8, Issue 10, 2019, Pp.2667-2671.

\section{AUTHOR PROFILE}

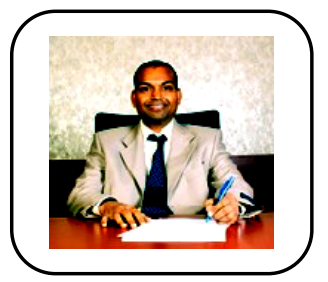

K Viswanath Allamraju, faculty in ME Department at Institute of Aeronautical Engineering (Autonomous), Dundigal, Hyderabad, India. He completed his M-Tech from MANIT Bhopal and $\mathrm{PhD}$ from NIT Warangal. His research areas are finite element method, neural networks, material characterization of metals and composite materials, vibration analysis and machine design. He has published more than 50 articles in various International journals (Scopus indexed). He had participated 60 International conferences at various IITs and IISC.

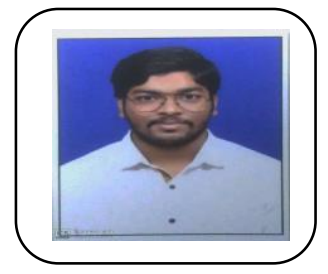

B. Sathya Sai Swaroop, UG student of Mechanical Engineering at Institute of Aeronautical Engineering (Autonomous), Dundigal, Hyderabad, India

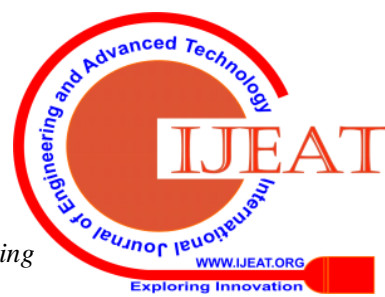


K.Sharath Kumar, UG student of Mechanical Engineering at Institute of Aeronautical Engineering (Autonomous), Dundigal, Hyderabad, India

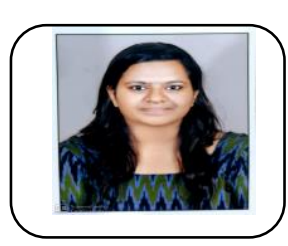

Ch. Vaishnavi Srinivas, UG student of Mechanical Engineering at Institute of Aeronautical Engineering (Autonomous), Dundigal, Hyderabad, India 